\title{
Changes in the electrocardiographic response to exercise in healthy women
}

\author{
Jaap W Deckers, Ruud V H Vinke, Jeroen R Vos, Maarten L Simoons
}

Thoraxcenter, Division of Cardiology, University Hospital Rotterdam "Dijkzigt" and Erasmus

University,

Rotterdam,

The Netherlands

J W Deckers

R V H Vinke

J R Vos

M L Simoons

Correspondence to Dr Jaap W Deckers, University Hospital

Rotterdam "Dijkzigt",
Thoraxcenter, Room Bd 381, Dr Molewaterplein 40, 3015 GD Rotterdam, The Netherlands.

Accepted for publication 19 June 1990

\begin{abstract}
Changes in the $P$ wave, QRS complex, ST segment, and $T$ wave during and after maximal exercise were quantitatively analysed in 116 healthy women with a mean age of 39 . The corrected orthogonal Frank lead electrocardiogram was continuously recorded and computer processed during bicycle ergometry. With exercise, maximal spatial $P$ wave vectors shifted downward. The $Q$ wave amplitude became more negative and the $R$ wave amplitude diminished considerably in leads $X$ and $Y$ : the $S$ wave amplitude decreased only slightly in these leads. The QRS vectors shifted towards right and posteriorly during exertion and a further shift in the same direction was seen in the recovery period. The ST segment amplitude $60 \mathrm{~ms}$ after the $J$ point decreased with exertion and became negative at heart rates above 140 beats per minute, in particular in lead $Y$. ST segment depression increased with age. The $T$ wave amplitude decreased during exercise and increased sharply in the recovery period. Though mean $R$ wave amplitude in leads $X$ and $Y$ became more negative with exercise, this response was unpredictable in individual women.
\end{abstract}

The exercise induced changes in QRS vectors in women resembled those described in men. Changes in the amplitude of the $R$ wave should not be used for the diagnosis of coronary disease in women. ST segment depression was more pronounced in the inferiorly oriented lead $Y$ than in lead $X$ but it was unrelated to changes in the QRS vectors in these leads.

Exercise electrocardiography is an established method of predicting the presence of coronary disease in men but its value in women remains controversial. ' Some studies have described considerable ST segment depression induced by exercise in symptom free women, ${ }^{2-4}$ and in those with no angiographic evidence of coronary obstructions..$^{5-7}$ Others claim that the value of the exercise test in women is similar to that in men, ${ }^{8-10}$ or that the high number of false positive tests in women can be attributed solely to their low prevalence of coronary disease. ${ }^{112}$ One study suggested that the diagnostic value of the test in women could be improved if exercise induced QRS changes were taken into account. ${ }^{13}$ Given these discrepancies, it is surprising that we know of no quantitative study of exercise induced electrocardiographic changes in women. Therefore, and in an attempt to elucidate possible sex differences in this response, we studied the electrocardiographic changes of the $P$ wave, QRS complex, ST segment, and $T$ wave during and after exercise in 116 female volunteers presumed to be free of cardiac disease.

\section{Subjects and methods}

One hundred and sixteen women performed a single exercise test. All were healthy volunteers without chest pain and without a history of cardiovascular disease. They had a normal electrocardiogram at rest, blood pressure of $\leqslant 165 / 95 \mathrm{~mm} \mathrm{Hg}$, and a fasting serum cholesterol concentration $<6.7 \mathrm{mmol} / 1$. Smoking history was not taken into account. They were not taking any medication. None had auscultatory findings suggestive of mitral valve prolapse or other forms of valve disease. Their mean (SD) age was 39 (10) years. Exercise tests were performed in the second half of 1978 . After a mean follow up period of more than four years, none of them had died although seven could not be traced or had emigrated. The electrocardiograms of these seven women were reviewed separately but were retained in the study because their electrocardiographic amplitudes fell within the 5th and 95th percentile limits of the other women.

The women exercised seated on a calibrated bicycle ergometer. The workload was increased by $10 \mathrm{~W}$ per minute. The test was terminated when the subjects neared exhaustion. Cycling was continued at a low load for $\mathbf{4}$ minutes after peak exercise. The electrocardiogram was recorded through corrected orthogonal Frank leads with the chest electrodes at the level of the fifth intercostal space. The $F$ electrode was placed on the sacrum and the $\mathbf{H}$ electrode on the neck. Careful attention was paid to proper preparation of the skin and fixation of the electrodes and wires. The electrocardiograms were computer processed as described in detail elsewhere.$^{14}$ In brief, the three orthogonal leads were sampled for 20 seconds with the subject at rest seated, every minute during exercise, and within six minutes of the end of exercise. The sampling frequency was $250 \mathrm{~Hz}$. Beats showing abnormal QRS complexes or excessive baseline drift were rejected. An average representative complex was calculated from the remaining beats. Templates were used to define the onset 
and termination of QRS complexes. ${ }^{15}$ The resting electrocardiogram of each subject was analysed with a general template. After visual inspection and validation of the reference points, patient specific templates were calculated and recorded. ${ }^{14}$ The onset, peak, and end of the $P$ and the $T$ wave were also determined. For each lead, $\mathbf{Q}, \mathbf{R}$, and $\mathbf{S}$ waves were located. The baseline level was defined as the mean signal amplitude 5 to 3 samples (20 to $12 \mathrm{~ms}$ ) before the QRS onset. All amplitudes were measured relative to this baseline. $S T_{60}$ denotes the ST amplitude $60 \mathrm{~ms}$ after the J point. Orthogonal electrocardiographic amplitudes were converted to 12 lead electrocardiogram V5 amplitude according to Dower. ${ }^{16}$

\section{STATISTICAL ANALYSIS}

Statistical analysis, which included paired $t$ tests to compare ST segment amplitudes and linear regression analysis and analysis of variance of electrocardiographic and clinical variables, was performed with the BMDP statistical program. Probability values of $<0.05$ were regarded as significant.

\section{Results}

The mean (SD) maximum workload achieved with exercise was $156(32) \mathrm{W}$ and the peak heart rate rose to 170 (16) beats $/ \mathrm{min}$. Systolic blood pressure rose from 137 (17) $\mathrm{mm} \mathrm{Hg}$ at rest to 195 (18) $\mathrm{mm} \mathrm{Hg}$ at peak exercise. Maximum heart rate and workload achieved decreased with age (table 1 ).

\section{ELECTROCARDIOGRAPHIC CHANGES \\ $P$ wave}

The interval between the maximal spatial magnitude of the $P$ wave and the onset of QRS complex decreased during exercise and lengthened again in the recovery period. Figure 1 shows the mean values of $P$ amplitude in leads $X, Y$, and $Z$ at increasing heart rates during exercise and at decreasing heart rates in the recovery period. $P$ wave amplitude in leads $X$ and $Y$ (especially in lead $Y$ ) increased with exercise. The changes represent a gradual shift in the maximal $\mathbf{P}$ wave amplitude anteriorly, leftwards, and downwards. $P$ wave amplitude at corresponding heart rates was higher in the recovery period than during exercise.

Table 1 Mean (SD) maximal heart rate, achieved workload, and $S T$ segment amplitudes at peak exercise measured 80 ms after $J$ in Frank leads $X$ and $Y$ in 116 healthy women in three age groups

\begin{tabular}{llll}
\hline \multicolumn{4}{c}{ Age $(y r)$} \\
\cline { 2 - 4 } Variable & $\begin{array}{l}<0 \\
(n=25)\end{array}$ & $\begin{array}{l}30-49 \\
(n=76)\end{array}$ & $\begin{array}{l}>50 \\
(n=15)\end{array}$ \\
\hline $\begin{array}{l}\text { Peak heart rate } \\
\text { (beats/min) }\end{array}$ & $170(21)$ & $161(23)$ & $152(25)$ \\
Workload (W) & $172(32)$ & $154(30)$ & $134(35)$ \\
ST $_{80}$ lead X $(\mu \mathrm{V})$ & $30(51)$ & $18(45)$ & $22(44)$ \\
$\mathrm{ST}_{80}$ lead Y $(\mu \mathrm{V})$ & $10(50)$ & $-9(48)$ & $-20(44)$ \\
\hline
\end{tabular}

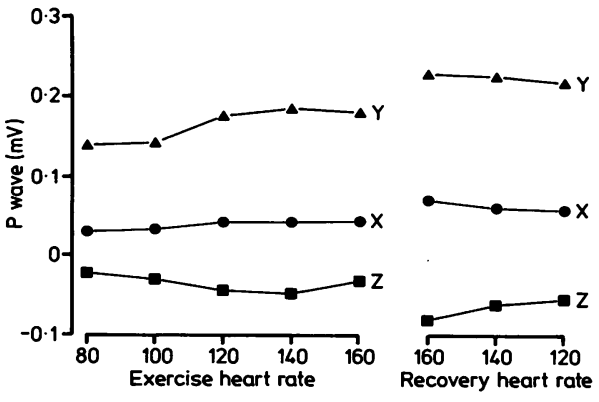

Figure 1 Changes in maximal $P$ wave amplitude in Frank leads $X, Y$, and $Z$ in women at heart rates of 80 $100,120,140$, and 160 beats/min during exercise, and at heart rates of 160,140 , and 120 beats per minute during recovery.

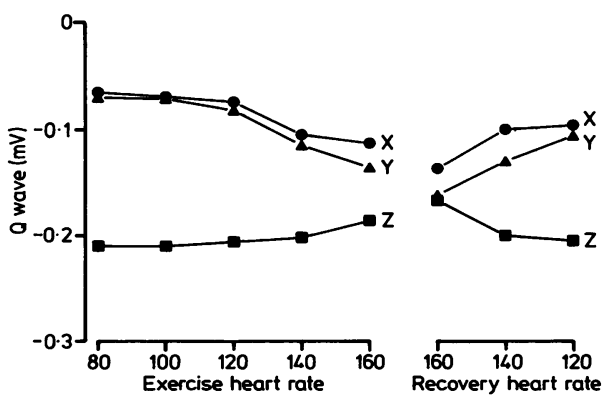

Figure 2 Changes in maximal $Q$ wave amplitude in Frank leads $X, Y$, and $Z$ in women at different heart rates during exercise and recovery.

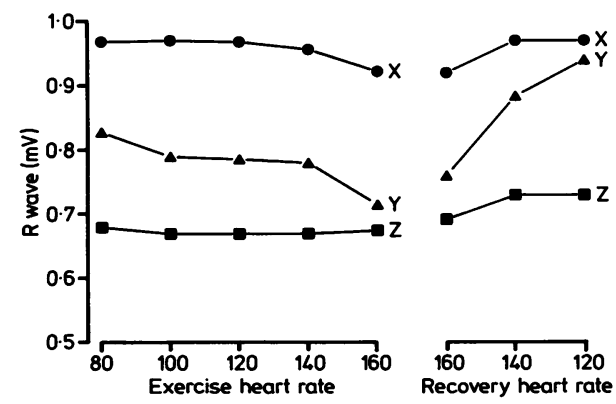

Figure 3 Changes in maximal $R$ wave amplitude in Frank leads $X, Y$, and $Z$ in women at different heart rates during exercise and recovery.

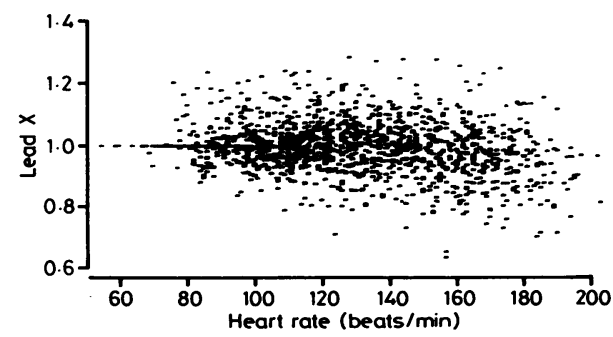

Figure 4 Individual changes in $R$ wave amplitude in lead $X$ during exercise in women. Measurements were made in relation to baseline $R$ wave values. 
Table 2 Changes in $R$ wave amplitude during exercise in Frank leads $X$ and $Y$ in 116 healthy women

\begin{tabular}{lcc}
\hline & Lead $X$ & Lead $Y$ \\
\hline Increase $>0.1 \mathrm{mV}(\%)$ & $7(6)$ & $6(5)$ \\
No change $(\%)$ & $70(60)$ & $7(6)$ \\
Decrease $>0.1 \mathrm{mV}(\%)$ & $31(27)$ & $65(56)$ \\
Decrease $>0.2 \mathrm{mV}(\%)$ & $8(7)$ & $38(33)$ \\
\hline
\end{tabular}

QRS COMPLEX

There was no significant change in QRS duration during exercise. The $Q$ wave became more negative in leads $\mathrm{X}$ and $\mathrm{Y}$ at the end of exercise and less negative in lead $Z$ (fig 2 ). The $R$ wave decreased during exercise in leads $\mathrm{X}$ and $\mathrm{Y}$ but became slightly more positive at the end of the test in lead Z (fig 3).

Though the amplitude of the $R$ wave decreased significantly during exercise, this response was extremely variable. Figure 4 shows the changes in $R$ wave amplitude in lead $X$ plotted against heart rate and the corresponding values at rest. In lead $X$ at peak exercise the amplitude of the $R$ wave decreased by at least $0 \cdot 1 \mathrm{mV}$ in 39 of the 116 women. Table 2 shows additional information on the $R$ wave changes during exercise. In concordance with the $\mathbf{R}$ wave response, the amplitude of the $S$ wave increased considerably at the end of exercise in leads $X$ and $Y$, but remained unchanged in lead $Z$ (fig 5). Taken as a whole the changes in the QRS complex correspond to a gradual shift of $Q R S$ vectors during exercise rightwards and posteriorly, with a further shift in the same direction in the recovery period.

\section{$S T$ segment}

ST segment amplitudes in leads $\mathrm{X}$ and $\mathrm{Y}$ decreased with increases in heart rate; but significantly more so in the inferiorly oriented lead. Figures $6 \mathrm{~A}$ and $6 \mathrm{~B}$ show $\mathrm{ST}$ segment amplitude in leads $\mathrm{X}$ and $\mathrm{Y}$ plotted against heart rate. Many of the ST measurements were in the lower range or even outside the 5 and 95 percentile limits previously reported in male volunteers. ${ }^{17} \mathrm{ST}$ segment depression was significantly $(\mathrm{p}<0.001)$ more pronounced in lead $\mathrm{Y}$ than in lead $\mathrm{X}$ at heart rate between 100 and 160 beats $/ \mathrm{min}$. For instance, in lead $X$ at a heart rate of 140 beats $/ \mathrm{min}$ mean (SD) $S T_{60}$ was

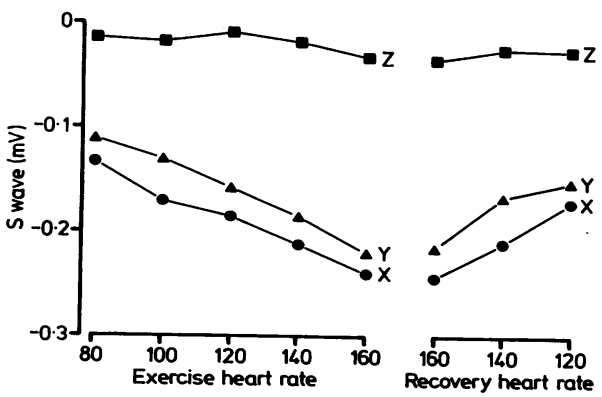

Figure 5 Changes in maximal $S$ wave amplitudes in Frank leads $X, Y$, and $Z$ in women at different heart rates during exercise and recovery.
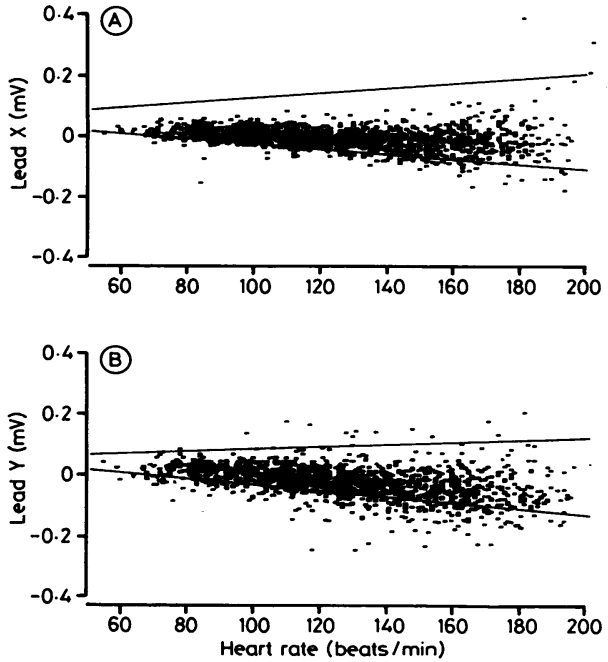

Figure 6 Individual changes in $S T$ segment amplitude in Frank leads $X(A)$ and $(B) Y 60$ ms after the $J$ point in women during exercise. The 5 and 95 percentile limits for the same measurement in male volunteers are shown."

$-0.015(0.032)\left(\mathrm{ST}_{80}, 0.019(0.040)\right) \mathrm{mV}$. At the same heart rate in lead $\mathrm{Y}, \mathrm{ST}_{60}$ was -0.037 $(0.046) \mathrm{mV}\left(\mathrm{ST}_{80},-0.021(0.055) \mathrm{mV}\right) . \mathrm{ST}_{60}$ in the computed lead $\mathrm{V} 5$ at a heart rate of 140 beats/min was also negative $(-0.011)\left(\mathrm{ST}_{80}\right.$, $0.028) \mathrm{mV}$. ST segment amplitudes in leads $\mathrm{X}$ and $\mathrm{Y}$ became less negative at very high heart rate levels. To test the hypothesis that the different ST segment response in leads $X$ and $Y$ was related to changes in, or absolute values of, $\mathrm{R}$ wave amplitude, ST segment amplitude changes were adjusted for $R$ wave amplitude at rest and at peak exercise in the various leads. No relation, however, was found between these electrocardiographic variables. ST segment amplitude became more negative with increasing age (table 1), and was thus associated with changes in heart rate as well as with age. This was particularly true in lead $\mathrm{Y}$ at heart rates of $\leqslant 160$ beats per minute. Figure 7 shows ST segment changes during exercise in relation to the ST segment amplitudes in these leads at rest; this shows the different behaviour of the

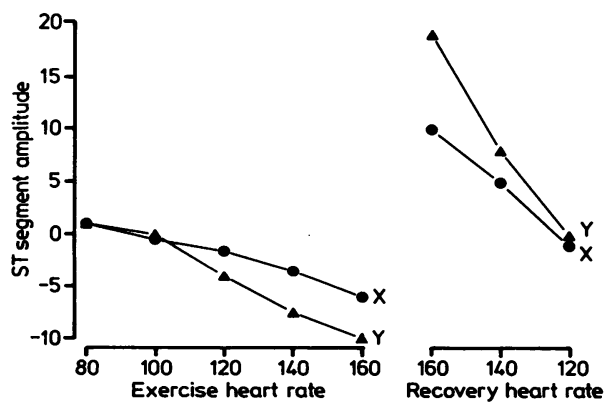

Figure 7 Changes in ST segment amplitude in Frank leads $X$ and $Y 60$ ms after the $J$ point at different heart rates during exercise and recovery in women. The measurement is given in relation to baseline $S T$ segment amplitudes. 


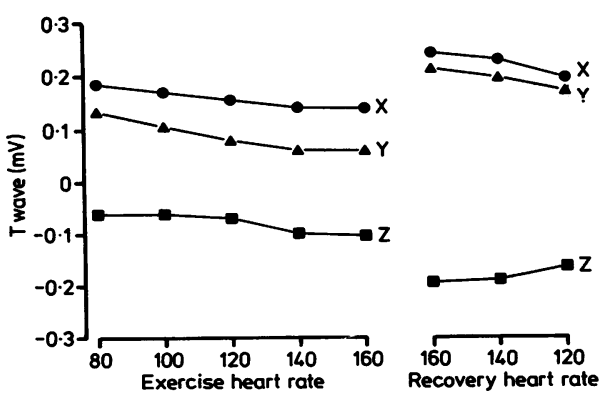

Figure 8 Changes in maximal $T$ wave amplitudes in Frank leads $X$ and $Y$ in women at different heart rates during exercise and recovery.

ST segment response in lead $\mathrm{X}$ and $\mathrm{Y}$ during exercise in women.

\section{Twave}

During exercise the QT interval gradually shortened. $T$ wave amplitude decreased early during exercise, but increased sharply in all leads immediately after the end of exertion (fig 8). There was a shift of the $T$ wave rightwards and superiorly that was linearly dependent on heart rate during exercise.

\section{Discussion}

The continuing controversy about the clinical significance of electrocardiographic changes in women during exercise has limited the usefulness of the test. ${ }^{1819}$ Reference values for the exercise induced electrocardiographic changes and variations in this response have been accurately established in men, ${ }^{20-22}$ but not in women.

Our study had limitations. We studied healthy women with a mean age of 39 years; the results may be different in older women with symptoms who are screened for coronary artery disease in various clinical or outpatient settings. Also the exercise tests were performed ten years ago; but we doubt that there were significant secular trends in the characteristics of healthy women during this time. The observed association between age and ST segment change should be considered in the light of the small number of elderly women in our study group. The study subjects did perform a maximal stress test-as indicated by the workload achieved, the peak heart rate, and systolic blood pressure. ${ }^{323}$

Our study showed that with exercise maximal $\mathbf{P}$ wave vectors shifted predominantly downwards, whereas maximal QRS vectors shifted to the right and posteriorly. The observed changes in $P$ wave, $Q R S$ complex, and $T$ wave in women resemble those described in men. ${ }^{172021}$

Bonoris et al and Baron et al suggested that an increase in $R$ wave amplitude during exercise was of diagnostic importance, ${ }^{24} 25$ but the present results, indicating a highly unpredictable individual $R$ wave response, do not support this. Others were also unable to confirm the diagnostic value of $R$ wave amplitude changes. ${ }^{26-28}$ Part of the reported differences between $R$ wave changes in subjects with and without coronary disease may be the result of differences in peak heart rate during the test. For example, Ilsley et al found that women with coronary disease had lower peak heart rates than those without ( 107 beats/min $v$ 130 beats/min). ${ }^{13}$ In our study, mean $R$ wave amplitude decreased during peak exercise in leads $X$ and $Y$, but individual $R$ wave changes were highly variable. In many tests $R$ wave amplitude did not change or even increased either at the end of exercise or during lower levels of exercise. This phenomenon, also reported by others, ${ }^{21}$ shows that $R$ wave changes should not be used for the diagnosis of coronary disease in women. We performed a detailed analysis of the change in ST segment amplitude during exercise. ST segment amplitude in leads $X$ and $Y$ decreased significantly as heart rate increased: these changes which were augmented by age, were most noticeable in lead $Y$ at heart rates of $120-160$ beats $/ \mathrm{min}$. Our data indicate that in response to exercise $S$ wave vectors behaved similarly in these leads, making it unlikely that the behaviour of the $S$ wave was responsible for this finding. Like others, ${ }^{29}$ we did not find a relation between the height of the $R$ wave and subsequent $S T$ segment depression in that lead.

Many reports have examined the diagnostic and prognostic value of exercise induced ST segment changes in women. In symptom free, healthy volunteers, ST segment depression of $\geqslant 1 \mathrm{~mm}$ was reported in $2 \%^{30}$ to $50 \%$ of middle aged women. ${ }^{34}$ In follow up studies, exercise induced ST segment depression proved to be a poor predictor of future coronary events in symptom free women and in those with atypical chest complaints. ${ }^{91031}$ In a review by Guiteras et $a l,,^{32}$ the specificity of the exercise electrocardiogram in women with normal coronary arteries ranged from $63 \%$ to $92 \% .^{1133}$ Leading studies that compared ST segment changes in women with those in men always found that the specificity in men was slightly higher. ${ }^{7112}$ For example, in the large series reported by Weiner et al, the specificity of the electrocardiographic response to exercise in the total population was $74 \%$ in men compared with $64 \%$ in women. ${ }^{12}$ However, in a paired subgroup matched for age and the presence and extent of coronary artery disease, no statistically significant differences were found between men and women in the percentages of false positive and false negative results. Although the present findings suggest that there is indeed a different $S T$ segment response with higher heart rates in men and women, these conclusions have to be interpreted with some caution. The two studies were not performed at the same time in our institution and the mean age of the men was higher. ${ }^{17}$ On the other hand, given the predominance of younger women in this study and the observation that ST segment depression increases with age, the present study may actually have underestimated the prevalence of ST segment depression in middle aged women. The conclusion that the prevalence of $S T$ segment depression in women increases with age is supported by other reports. ${ }^{23} 30$ 
The present quantitative data indicate that ST segment depression is especially common in women at high heart rates in the inferiorly oriented lead Y. Sketch et al too reported that a higher ST segment depression was more common in leads II, III, and aVF in 46 women without significant coronary disease. ${ }^{1}$ Guiteras et al too found that the specificity of the exercise induced ST segment depression in women was dependent on the electrocardiographic lead chosen, with lowest specificity in leads II, III, aVF, V5, and CM5. ${ }^{32}$

Mechanisms that may contribute to the changes in $P$ waves, QRS complexes, and ST segment during exercise have been summarised elsewhere. ${ }^{1720}$ Changes in the position of electrodes relative to the heart, in the ionic balance, in haematocrit, and in intracardiac volume have all been implicated. There is no evidence that any one of these mechanisms acts differently in the two sexes and it seems unlikely that any of these factors can explain the different ST segment response to exercise in women. On the other hand, the observation that ST segment depression during exercise is more common in women cannot be explained solely by the lower incidence of coronary disease in women. ${ }^{11}$ Other studies are warranted to identify this so-called non-Bayesian factor.

Our results indicate that in women exercise induced a downward shift of maximal $P$ vectors and a shift rightwards and posteriorly of QRS vectors. This resembled the response in healthy men. Changes in $R$ wave amplitude were unpredictable and should not be used for the diagnosis of coronary disease in women. ST segment depression increased with heart rate and with age. ST segment depression was more pronounced in lead $\mathrm{Y}$ than in lead $\mathrm{X}$, though changes in $S$ wave amplitude were similar in both leads.

We thank Dr Phons Fels and Dr Nel Verbaan, who selected the volunteers and performed the exercise tests; $L$ eon van Adrichem and Ruud de Waal for their help with the follow up data; and Jan Tijssen for help with the statistical analysis.

1 Sketch MH, Mohiuddin SM, Lynch JD, Zencka AE, Runco V. Significant sex differences in the correlation of electrocardiographic exercise testing and coronary arteriograms. Am J Cardiol 1975;36:169-73.

2 Astrand I. Exercise electrocardiograms recorded twice with an 8-year interval in a group of 204 women and men 48-63 years old. Acta Med Scand 1965;178:27-39.

3 Profant GR, Early RG, Nilson KL, Kusumi F, Hofer V, Bruce RA. Responses to maximal exercise in healthy middle-aged women. $J$ Appl Physiol 1972;33:595-9. 4 Cumming GR, Dufresne C, Kich L, Samm J. Exercise
electrocardiogram patterns in normal women. Br Heart J 1973;35:1055-6i.

5 Caru B, Sozzi G, Ciliberto R. Corrélations entre épreuve d'effort et coronarographie chez la femme. In: Broustet JP, Bricaud H, Denolin H, eds. Les épreuves d'effort. Paris: Expansion Scientifique Française, 1978:57-66.

6 Broustet JP, Castan R, Emeriau JP, Besse P, Bricaud H. Approche multifactorielle de l'angor féminin a coronaires normales. In: Broustet JP, Bricaud H, Denolin H, eds. Les épreuves d'effort. Paris: Expansion Scientifique Française, 1978:85-114.

7 Barolsky SM, Gilbert CA, Faruqui A, Nutter DO, Schlant RC. Differences in electrocardiographic response to exercise of women and men: a non-Bayesian factor. Circulation 1979;60:1021-7.
8 Linhart JW, Laws JG, Satinsky JD. Maximum treadmil exercise electrocardiography in female patients. Circula tion 1974;50:1173-8.

9 Allen WH, Aronow WS, De Cristofaro D. Treadmil exercise testing in mass screening for coronary risk factors. Cathet Cardiovasc Diagn 1976;2:39-48.

10 Bengtsson C, Grimby G, Lindquist O, Noppa $H$, Sigurdsson JA, Vedin JA. Prognosis of women with exercise-induced ECG changes-results from a longitudinal population study. Cardiology 1981;68:(suppl 2): $9-14$

11 Detry JMR, Kapita BM, Cosyns J, Sottiaux B, Brasseur LA Rousseau MF. Diagnostic value of history and maximal exercise electrocardiography in men and women suspected of coronary heart disease. Circulation 1977;56:756-61.

12 Weiner DA, Ryan TJ, McCabe CH, et al. Exercise stress testing. Correlations among history of angina, ST segment response and prevalence of coronary artery disease in the Coronary Artery Surgery Study (CASS) N Engl J Med 1979;301:230-5.

13 Ilsley C, Canepa-Anson R, Westgate C, Webb S, Rickards $A F$, Poole-Wilson $P$. Influence of $R$ wave analysis upon diagnostic accuracy of exercise testing in women. Br Heart J 1982;48:161-8.

14 Simoons ML, Boom HB, Smallenburg E. On-line processing of orthogonal exercise electrocardiograms. Comput Biomed Res 1975;8:105-17.

15 van Bemmel JH, Talmon JLC, Duisterhout JS, Hengeveld SJ. Template waveform recognition applied to ECG/ VCG analysis. Comput Biomed Res 1973;6:430-41.

16 Dower GE. Polarcardiography. Springfield, Illinois: Charles C Thomas, 1971

17 Simoons ML, Hugenholtz PG. Gradual changes of ECG waveform during and after exercise in normal subjects. Circulation 1975;52:570-7.

18 Melin A, Wijns W, Vanbutsele RE, et al. Alternative diagnostic strategies for coronary artery disease in women: demonstration of the usefulness and efficiency of probability analysis. Circulation 1985;71:535-42.

19 Pratt CM, Francis MJ, Divine GW, Young JB. Exercise testing in women with chest pain. Are there additional exercise characteristics that predict true positive test results? Chest 1989;95:139-44.

20 Wolthuis RA, Froelicher VF, Hopkirk A, Fischer JR, Keiser $N$. Normal electrocardiographic waveform characteristics during treadmill exercise testing. Circulation 1979;60 1028-35

21 Froelicher VF, Wolthuis R, Fischer J, Uhl G. Variations in normal electrocardiographic response to treadmill testing. Am J Cardiol 1981;47:1161-7.

22 Kasser IS, Bruce RA. Comparative effects of aging and coronary heart disease on submaximal and maximal exercise. Circulation 1969;39:759-74.

23 Londeree BR, Moeschberger ML. Influence of age and other factors on maximal heart rate. Cardiol Rehabil 1984;4:44-9.

24 Bonoris PE, Greenberg PS, Castellanet MJ, Ellestad MH. Significance of changes in $R$ wave amplitude during treadmill stress testing: angiographic correlation. $\mathrm{Am}$ Cardiol 1978;41:846-51.

25 Baron DW, Ilsley C, Sheiban I, Poole-Wilson PA, Rickard AF. $R$ wave amplitude during exercise. Relation to left ventricular function and coronary artery disease, $\mathrm{Br}$ Heart $J$ 1980;44:512-7.

26 Battler A, Froelicher V, Slutsky R, Ashburn W. Relationship of $Q R S$ amplitude changes during exercise to left ventricular function and volumes and the diagnosis of coronary artery disease. Circulation 1979;60:1004-13.

27 Fox K, England D, Jonathan A, Selwyn A. Inability of exercise-induced $\mathbf{R}$ wave changes to predict coronary artery disease. Am J Cardiol 1982;49:674-9.

28 Hopkirk JAC, Uhl GS, Hickman JR, Fischer J Limitation of exercise-induced $R$ wave amplitude changes in detecting coronary artery disease in asymptomatic men. $J \mathrm{Am}$ Coll Cardiol 1984;3:821-6.

29 Detrano R, Salcedo E, Passalacqua M, Friis R. Exercise electrocardiographic variables: a critical appraisal. $J \mathrm{Am}$ Coll Cardiol 1986;8:836-47.

30 Aronow WS, Cassidy J, Uyeyama RR. The resting and postexercise phonocardiogram and electrocardiogram in asymptomatic women. Cardiology 1970;55:333-9.

31 Manca C, Dei Cas L, Albertini D, Baldi G, Visioli O. Different prognostic value of exercise electrocardiogram in men and women. Cardiology 1978;63:312-9.

32 Guiteras PV, Chaitman BR, Waters DD, et al. Diagnostic accuracy of exercise ECG lead systems in clinical subsets of women. Circulation 1982;65:1465-74.

33 Cahen $\mathbf{P}$, Quard $S$, Chazaud $P$, et al. Valeur diagnostique de l'épreuve d'effort chez la femme: comparaison avec la coronarographie. In: Broustet JP, Bricaud $\mathrm{H}$, Denolin $\mathbf{H}$, eds. Les épreuves d'effort. Paris: Expansion Scientifique Française, 1978:67-81. 